\title{
Interrelationship between insistence on sameness, effortful control and anxiety in adolescents and young adults with autism spectrum disorder (ASD)
}

\author{
Mirko Uljarević ${ }^{1,2^{*}}$, Amanda L. Richdale ${ }^{1,2}$, David W. Evans ${ }^{3}$, Ru Ying Cai ${ }^{1,2}$ and Susan R. Leekam ${ }^{4}$
}

\begin{abstract}
Background: Both self-regulation and insistence on sameness (IS) are related to anxiety, which is a common feature of individuals with autism spectrum disorder (ASD). Here, we aimed to characterise the IS-self-regulationanxiety interrelationship by investigating the potential contribution made by self-regulation, assessed via effortful control (EC), to the IS-anxiety relationship in a sample of adolescents and young adults with ASD.

Method: Seventy-one older adolescents and younger adults with ASD (49 males, 22 females; $M_{\text {age }}=18.71$ years, $\mathrm{SD}=2.51$, range 14.42-24.81) completed the Adult Repetitive Behaviour Questionnaire-2, Effortful Control Scale of the Adult Temperament Questionnaire and the DSM-5 Dimensional Anxiety Scales.

Results: IS was associated with both EC $(r=-.39, p=.001)$ and anxiety $(r=.45, p<.001)$, and anxiety was in turn associated with EC $(r=-.44, p<.001)$. To characterise the nature of this interrelationship, two mediation analyses were performed using the serial mediation model in PROCESS with 5000 resamples in bootstrapping. There was a significant indirect effect of EC on anxiety, through IS ( $b=-.06$; BCa $95 \% \mathrm{Cl}[-.13,-.02])$, and indirect effect on anxiety through $\mathrm{EC}(b=1.62 ; \mathrm{BCa} 95 \% \mathrm{Cl}[.59,3.24])$ with the mediators accounting for 29.07 and $26.04 \%$ of the total effect, respectively.

Conclusions: Our study provides the first exploration of the IS-anxiety-self-regulation link in ASD. The finding that lower levels of self-regulation are related both to anxiety and IS behaviours points to self-regulation as a viable intervention target for both anxiety and IS behaviours.
\end{abstract}

Keywords: Insistence on sameness, Effortful control, Self-regulation, Anxiety, Autism

\section{Background}

Insistence on sameness (IS) refers to complex patterns of rigid, routinised, and ritualistic behaviours that form a class of restrictive and repetitive behaviours (RRBs) and a diagnostic criterion for autism spectrum disorder (ASD) [1]. These behaviours are also part of typical development where they are transient in nature and often serve an adaptive role [2-6]. During the early

\footnotetext{
* Correspondence: m.uljarevic@latrobe.edu.au

'Olga Tennison Autism Research Centre, School of Psychological Science, La Trobe University, Bundoora, VIC 3086, Australia

${ }^{2}$ Cooperative Research Centre for Living with Autism (Autism CRC), Level 3 Foxtail Building, Long Pocket, The University of Queensland, Brisbane, QLD 4072, Australia

Full list of author information is available at the end of the article
}

development of most children, IS behaviours and typical fears and anxiety, such as fear of strangers, as well as cognitively more complex and anticipatory fears tend to follow a similar developmental trajectory [2, 4, 7-10]. Furthermore, normative IS behaviours are likely to occur at times of transition, such as bedtime or mealtime, and are often accompanied by typical fears/anxieties, including fear of the dark or separation anxiety [3]. These observations have led to the suggestion that IS behaviours act as an early form of self-regulation, serving to control or constrain the environment thus limiting unpredictability and reducing ensuing fears and anxiety, eventually reducing as more advanced forms of self-regulation develop [5, 11-14]. In individuals with ASD, IS behaviours 
tend to be relatively stable over time [15] and negatively impact the functioning of individuals and their families $[5,16]$. It is possible that IS behaviours continue to serve a regulatory function in ASD beyond the period when they are adaptive thus negatively affecting development and, in particular, sustaining anxiety. However, this proposal has not been previously tested.

Self-regulation abilities include attentional control, inhibition of dominant and activation of subdominant responses and ability to shift between multiple tasks and/ or mental sets. While cognitive and clinical researchers have traditionally assessed these abilities via measures of executive functioning (EF), developmental psychology researchers have considered self-regulation from a temperament perspective and used measures of effortful control (EC). The majority of the research has identified an overlap between EF and EC constructs, at a conceptual level, and also in terms of their developmental trajectory, genetic and neurodevelopmental underpinnings and outcomes/correlates [17, 18]. EF and EC abilities develop gradually, becoming progressively more advanced and complex between early toddlerhood and school years [17-19], a period during which both IS behaviours and fears gradually decrease. Research indicates that individual variation in EF and EC during this normative developmental period relates to the levels of IS behaviours $[10,20]$ and also predicts later internalizing problems [21-23]. Thus, it seems that the development of more sophisticated and flexible EF and EC forms during childhood results in less reliance on IS behaviours for managing fears [3]. Furthermore, it is reasonable to hypothesise that IS behaviours, if persistent beyond the developmental period when they are adaptive, may negatively impact subsequent development by limiting children's exposure to situations conducive to developing more elaborate, complex and flexible patterns of EF and EC, as well as other aspects of social, cognitive and emotional development $[5,24]$.

A large body of research in ASD indicates significant impairments in EF and EC [25-28]. These impairments have been linked to increased internalizing problems, in particular, anxiety [25, 26, 29-31], as well as with RRBs [5]. In turn, anxiety is associated with higher levels of RRBs, most notably, IS behaviours [32-35]. However, the nature of the IS-EF and EC-anxiety interrelationship has not been explored previously in the ASD literature.

Based on the reviewed literature from both typical development and ASD, lower levels of self-regulation, operationalised as either EC or EF, and higher levels of IS behaviours may both be expected to be related directly to higher levels of anxiety. Additionally, IS and self-regulation might also have an indirect effect on anxiety in the following two ways: (1) the association between self-regulation and anxiety is mediated by IS and
(2) the association between IS behaviours and anxiety is mediated by self-regulation. Therefore the aim of this study was to provide the first characterisation of the IS-self-regulation-anxiety interrelationship in a crosssectional sample of older adolescents and young adults with ASD, using EC as a measure of self-regulation.

\section{Methods}

\section{Participants}

Seventy-one adolescents and young adults with ASD (49 males, 22 females; $M_{\text {age }}=18.71$ years, $\mathrm{SD}=2.51$, range 14.42-24.81) took part in the study. Participants were recruited through various channels including state-based autism organisations, parent support groups, secondary and tertiary education organisations, participant databases and clinicians. All participants self-reported a clinical diagnosis of ASD $(N=24$ ASD, 34 Asperger syndrome, 8 high-functioning autism, 4 autistic disorder, 1 PDD-NOS). The abridged version of the Autism Spectrum Quotient (AQ-28) [36] was used to confirm the autism characteristics. All participants exceeded the suggested AQ-28 score cut-off of $>65$ which has a sensitivity of .97 and a specificity of .82 for ASD. See Table 1 for descriptives.

\section{Procedures and measures}

The results presented here form part of the nationwide Longitudinal Study of Australian Schools Leavers with ASD and their families within the Cooperative Research Centre for Living with Autism (Autism CRC) which was approved by the La Trobe University Human Ethics Committee and other institutional or organisational ethics committees as appropriate.

Adult Repetitive Behaviours Questionnaire-2 (RBQ2A) [37] is a self-report version of the original RBQ-2 [4] designed to measure a range of repetitive behaviours. The RBQ-2A has a stable two-factor structure with repetitive sensory-motor (RSM) and IS factors consistently identified across both normative development and in ASD [37].

Table 1 Descriptive statistics

\begin{tabular}{lllll}
\hline & Mean (SD) & $\begin{array}{l}\text { Sample } \\
\text { range }\end{array}$ & $\begin{array}{l}\text { Possible } \\
\text { range }\end{array}$ & $\begin{array}{l}\text { Shapiro-Wilk } \\
\text { test (sig) }\end{array}$ \\
\hline $\begin{array}{l}\text { Chronological } \\
\text { age }\end{array}$ & $\begin{array}{l}18.71 \\
(2.51)\end{array}$ & $14.42-24.81$ & $\mathrm{NA}$ & $p=.006$ \\
AQ-28 & $\begin{array}{l}77.94 \\
(8.93)\end{array}$ & $67-104$ & $28-112$ & $p=.001$ \\
Anxiety & $\begin{array}{l}12.90 \\
(8.01)\end{array}$ & $0-31$ & $0-36$ & $p=.015$ \\
& $2.17(.58)$ & $1.13-3.75$ & $1-3$ & $p=.34$ \\
IS & $\begin{array}{l}68.11 \\
\text { Effortful control }\end{array}$ & $33-103$ & $19-152$ & $p=.78$ \\
& $(16.65)$ & & & \\
\hline
\end{tabular}

Note: IS score is calculated as mean (see Barrett et al. [37] for detail) NA not applicable 
Effortful Control Domain of the Adolescent/Adult Temperament Questionnaire [38] was used as a measure of self-regulation. It consists of 19 items assessing individual differences in the ability to perform actions when there is a strong tendency to avoid it, to focus and shift attention and to supress inappropriate approach behaviours. It is particularly geared toward attentional (example item: "When I am trying to focus my attention, I am easily distracted") and inhibitory (example item: "It is easy for me to inhibit fun behaviour that would be inappropriate") aspects. Higher scores indicate better EC capacity.

DSM-5 Dimensional Anxiety Scales (DSM-5 DAS) [39-41] is a brief screening questionnaire designed to provide both dimensional assessment of anxiety symptoms, as well as a threshold score (14) identifying clinically significant anxiety [41].

\section{Results}

Internal consistency analysis (Cronbach's $\alpha$ ) for IS, anxiety and EC scales were 78, .92 and .84, respectively. The cut-off score for clinically significant anxiety was met by $40.6 \%$ of participants. All of the analyses were conducted using bootstrapping with 1000 resamples in order to generate more reliable, robust statistics. Females had significantly higher anxiety $(17.12[\mathrm{SD}=8.73]$ vs 10.93 [SD $=6.90], F=10.15, p=.002$, Cohen's $d=.79)$ and IS $(2.41[\mathrm{SD}=.57]$ vs $2.07[\mathrm{SD}=.56], F=5.39, p=.023$, Cohen's $d=.60)$ scores. Although males had higher EC scores $(69.31[\mathrm{SD}=17.97]$ vs $66.32[\mathrm{SD}=13.53])$, this difference did not reach statistical significance $F=.48$, $p=.49$, Cohen's $d=.19$.

Preliminary analysis showed no statistically significant association between chronological age and IS behaviours, anxiety, or effortful control scores. IS was associated with both EC (Pearson correlation coefficient $[r]=-.39, p=.001, \mathrm{BCa} 95 \% \mathrm{CI}[-.55 ;-.20])$ and anxiety $(r=.45, p<.001, \mathrm{BCa} 95 \% \mathrm{CI}[24 ; .63])$, and anxiety was in turn associated with EC $(r=-.44, p<.001, \mathrm{BCa}$ $95 \%$ CI $[-.60 ;-.27])$. There were no statistically significant differences between males and females in terms of direction and strength of correlations between anxiety, IS and EC (anxiety-IS correlations comparison: Fisher's $z=.66, p=25$; IS-EC correlations comparison: $z=-.31$, $p=.39$; anxiety-EC comparison: $z=-1.88, p=.06$ ). Therefore, the subsequent analyses were performed on the whole sample. In order to characterise this interrelationship, two mediation analyses were performed using the serial mediation model in PROCESS. PROCESS is a computational tool for mediation, moderation and mediated moderation that is run under Statistical Package for Social Science software (SPSS; version 21.0; [42]). The Bias-Corrected Accelerated Bootstrapped 95 percentile Confidence Intervals (BCa 95CI) with 5000 resamples was used as an inferential test for indirect effects in mediation analysis [43]. Indirect effects where $\mathrm{BCa} 95 \mathrm{CI}$ do not span zero are deemed as significant. Bias-Corrected Accelerated Bootstrapping method has advantages over the classic Baron and Kenny's causal steps logic [44] as it does not require direct effect to be significant for a mediation to occur, and unlike Sobel test [45], it does not require data to be normally distributed [43]. Finally, it adjusts for measurement error when indirect effect is interpreted [46].

The first mediation model exploring whether the relationship between effortful control and anxiety was mediated by IS (see Fig. 1) was supported. A significant indirect effect of effortful control on anxiety, through IS, was found, $b=-.06$; BCa 95\% CI $[-.13,-.02]$. The mediator accounted for $29.7 \%$ of the total effect (percent mediation $[\mathrm{Pm}]=.29, \mathrm{BCa} 95 \% \mathrm{CI}[.10, .65])$.

The second mediation model (see Fig. 2) exploring whether the relationship between IS behaviours and anxiety was mediated by effortful control was also supported. IS had an indirect effect on anxiety through effortful control, $b=1.62$; BCa 95\% CI [.59, 3.24]. The mediator accounted for approximately $26.04 \%$ of the total effect $(P m=.26$, BCa 95\% CI $[.08, .58])$.

\section{Discussion}

Consistent with our predictions and previous literature $[3,10,14,25,29,34,35]$, our study indicates that IS is positively associated with anxiety and that higher levels of anxiety and IS are both associated with lower levels of EC. Furthermore, our mediation analyses showed that the association between EC and anxiety was mediated by IS and that, in turn, the relationship between IS behaviours and anxiety was mediated by EC. Additionally, $40.6 \%$ of adolescents and young adults from our sample met the DSM-5 DAS criterion for clinically significant anxiety, which is in line with systematic reviews and larger studies [47-49] that suggest $40 \%$ as the most realistic prevalence figure for a clinical anxiety disorder.

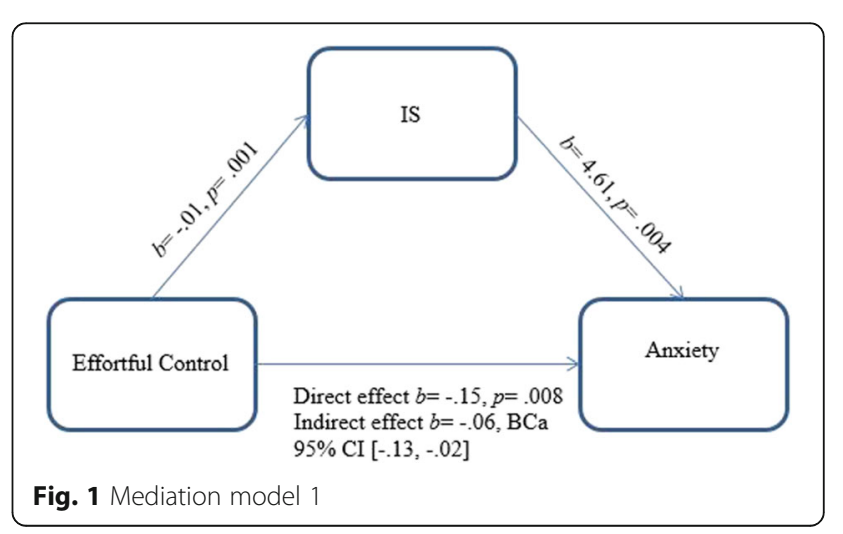




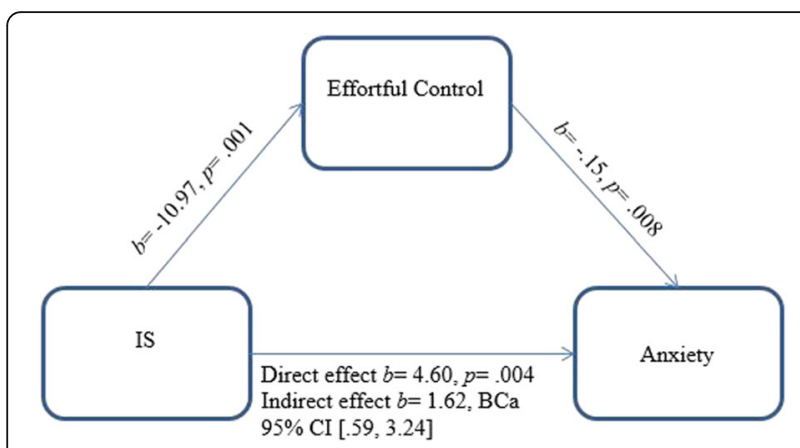

Fig. 2 Mediation model 2

IS behaviours have been implicated as playing similar roles in normative development and in neurodevelopmental and neuropsychiatric disorders by acting as a means of avoidance and thus reducing anxiety $[14,50]$. Whereas in normative development, IS behaviours are gradually replaced by more mature and flexible forms of self-regulation that effectively regulate distress and anxiety, in ASD, IS behaviours persist as the primary means of self-regulation. Consequently, the inflexibility of IS behaviours will likely reinforce anxiety in the long term $[34,51]$. Elevated and persistent IS behaviours can therefore impede the emergence of more developmentally appropriate modes of self-regulation in ASD, either because of the development of positive beliefs about the utility of IS $[34,51]$ or due to reduced exposure to situations that are conducive to developing more sophisticated self-regulatory strategies [10].

Using EC as a measure of self-regulation, our findings provide the first effort to disentangle the complex nature of the IS-anxiety-self regulation in the context of ASD. The mediation models offer support for both the developmental scenarios described above. Importantly, IS as mediator between EC and anxiety accounted for more variance than EC when mediating between IS and anxiety. These findings are nevertheless limited by the cross-sectional design, relatively older age of the sample, making the directionality of relationships difficult to establish. Cross-sectional designs are unable to capture these dynamic processes as they develop and unfold over time, and it is clear that a carefully designed longitudinal study, with a larger, well-characterised sample and multi-method assessments to avoid potential bias due to the common method variance, is necessary. In addition, due to the gender differences in anxiety and IS present in both typically developing and ASD populations $[5,52,53]$, it will be important for the future research to address potential differences in underlying mechanisms between males and females. The sample size used here was in line with other studies of this type, and the application of the Bias-Corrected Accelerated Bootstrapped 95th percentile confidence intervals test as a method has been shown to be more robust in studies with sample sizes such as ours [46] in order to test indirect effect. However, replication in a larger sample is needed. Therefore, although an important first step, our results should be considered as preliminary at this point. Nevertheless, they have potential implications for interventions targeting IS and anxiety in ASD.

Interventions specifically focused on RRBs in children with ASD and other neurodevelopmental disorders are rare $[54,55]$. Our findings suggest self-regulation as a viable intervention target as measured by EC. A number of interventions targeting both EC and EF, for example Tools of Mind [56], have been shown to increase executive attention in children aged 3-7 years [57]. Similar interventions have been shown to be effective in improving EF in children with attention-deficit hyperactivity disorder [58]. In addition, Unstuck on Target [59], a behavioural approach to develop flexibility and compensatory strategies for impairments in EF, has been shown to increase problem-solving, flexibility, and planning/organizing aspects of executive functioning based on experimental assessments and parental reports, as well as enabling easier transitions and improving flexibility within classrooms for children with ASD [60]. Therefore, it will be important in future work to explore the effects of these types of interventions on IS and anxiety.

\section{Conclusions}

Our study explored self-regulation and its relationship with IS and anxiety from a temperament perspective using a measure of EC. In ASD research, self-regulation has been mainly considered from an EF framework, and indeed, impairments in EF have been linked with repetitive behaviours, although with mixed results [5], as well as with anxiety [29, 31]. Although the majority of research suggests EC and EF to be largely overlapping constructs $[17,18]$, future research should consider selfregulation using measures from different theoretical frameworks, integrating measures of EC and EF, as well as a process model of emotion regulation [61]. Future progress in this area will rely on the study of selfregulation using measures of both EC and EF, as well as of emotion regulation, taken from multiple sources and from multiple informants, together with experimental/ laboratory tasks such as the Attention Network Test (ATN) [62] and intervention designs.

\section{Abbreviations \\ AQ: Autism Spectrum Quotient; ASD: Autism spectrum disorder; Autism CRC: Cooperative Research Centre for Living with Autism; EC: Effortful control; EF: Executive function(s); IS: Insistence on sameness}

Acknowledgements

MU, ALR and RYC acknowledge the financial support of the Cooperative Research Centre for Living with Autism (Autism CRC), established and supported under the Australian Government's Cooperative Research Centres 
program. We would like to thank all those who participated in the Longitudinal Study of Australian School Leavers with Autism.

\section{Funding}

This research is funded by the Cooperative Research Centre for Living with Autism (Autism CRC), established and supported under the Australian Government's Cooperative Research Centres Program.

\section{Availability of data and materials}

The datasets generated during and/or analysed during the current study are not publicly available due to them containing information that could compromise research participant consent.

\section{Authors' contributions}

MU conceived and designed the study, collected the data, analysed and interpreted the data and drafted the full original version of the manuscript. RYC conceived and designed the study, collected the data and provided input to the second version of the manuscript. ALR conceived and designed the study and provided input to the second version of the manuscript. DWE advised in terms of the analysis and provided input to the second version of the manuscript. SL advised in terms of the analysis and provided input to the second draft. All authors have provided comments on the drafts and approved the final version of the manuscript.

\section{Ethics approval and consent to participate}

All individuals read a participant information statement describing the study and provided written informed consent. Parental consent was also obtained for individuals under 18 years. Following consent, participants were sent a link to the online survey. Ethics applications for the two longitudinal studies were approved by the La Trobe University Human Ethics (HEC14-095).

\section{Consent for publication}

Not applicable

\section{Competing interests}

The authors declare that they have no competing interests.

\section{Publisher's Note}

Springer Nature remains neutral with regard to jurisdictional claims in published maps and institutional affiliations.

\section{Author details}

'Olga Tennison Autism Research Centre, School of Psychological Science, La Trobe University, Bundoora, VIC 3086, Australia. ${ }^{2}$ Cooperative Research Centre for Living with Autism (Autism CRC), Level 3 Foxtail Building, Long Pocket, The University of Queensland, Brisbane, QLD 4072, Australia. ${ }^{3}$ Department of Psychology, Bucknell University, Lewisburg, PA, USA. ${ }^{4}$ Wales Autism Research Centre, School of Psychology, Cardiff University, Cardiff, Wales, UK.

\section{Received: 15 March 2017 Accepted: 13 July 2017}

\section{Published online: 21 July 2017}

\section{References}

1. American Psychiatric Association. Diagnostic and statistical manual of mental disorders (5th ed.). Washington, DC: American Psychiatric Publishing; 2013.

2. Evans DW, Leckman JF, Carter A, Reznick JS, Henshaw D, King RA, Pauls D. Ritual, habit and perfectionism: the prevalence and development of compulsive-like behavior in normal young children. Child Dev. 1997;68:58-68.

3. Evans DW, Gray FL, Leckman JF. The rituals, fears and phobias of young children: insights from development, psychopathology and neurobiology. Child Psychiatry Hum Dev. 1999;29:261-76.

4. Leekam SR, Tandos J, McConachie H, Meins E, Parkinson K, Wright C, et al. Repetitive behaviors in typically developing 2-year-olds. J Child Psychol Psychiatry. 2007;48(11):1131-8.

5. Leekam SR, Prior MR, Uljarevic M. Restricted and repetitive behaviors in autism spectrum disorders: a review of research in the last decade. Psychol Bull. 2011;137(4):562-93.

6. Uljarević M, Arnott B, Carrington SJ, Meins E, Fernyhough C, McConachie H, Le Couteur A, \& Leekam SR. Development of restricted and repetitive behaviors from 15 to 77 months: stability of two distinct subtypes? Dev Psychol. 2017; accepted for publication.
7. Glenn S, Cunningham C. Typical or pathological? Routinized and compulsive-like behaviors in children and young people with down syndrome. Intellect Dev Disabil. 2007;45(4):246-56.

8. Gullone E. The development of normal fear: a century of research. Clin Psychol Rev. 2000;20(4):429-51.

9. Marks IM. Fears, phobias and rituals: panic, anxiety, and their disorders. Oxford: Oxford University Press; 1987.

10. Tregay J, Gilmour J, Charman T. Childhood rituals and executive functions. Brit J Dev Psychol. 2009;27(2):283-96.

11. Gesell A, Ames LB, Ilg FL. Infant and the child in culture today. New York, NY: Harper and Row; 1974.

12. Laing SV, Fernyhough C, Turner M, Freeston MH. Fear, worry and ritualistic behaviour in childhood: developmental trends and interrelations. Infant Child Dev. 2009;18:351-66.

13. Zohar AH, Felz L. Ritualistic behaviour in young children. JACP. 2011;29(2): 121-8.

14. Uljarević M, \& Evans DW. Relationship between repetitive behaviours and fears across normative development, autism spectrum disorder and down syndrome. Autism Res. 2016;10(3):502-07.

15. Esbensen AJ, Seltzer M, Lam K, Bodfish JW. Age-related differences in restricted repetitive behaviors in autism spectrum disorders. J Autism Dev Disord. 2009;39:57-66

16. Harrop C, McBee M, Boyd BA. How are child restricted and repetitive behaviors associated with caregiver stress over time? A parallel process multilevel growth model. J Autism Dev Disord. 2016;46(5):1773-83.

17. Bridgett DJ, Oddi KB, Laake LM, Murdock KW, Bachmann MN. Integrating and differentiating aspects of self-regulation: effortful control, executive functioning, and links to negative affectivity. Emotion. 2013;13:47-63.

18. Zhou Q, Chen SH, Main A. Commonalities and differences in the research on children's effortful control and executive function: a call for an integrated model of self-regulation. Child Dev Perspect. 2011;6(2):112-21.

19. Zelazo PD, Muller U, Frye D, Marcovitch S, Argitis S, Boseovski J, et al. The development of executive function in early childhood. Monogr Soc Res Child Dev. 2003:68(3):vii-137.

20. Pietrefesa A, Evans DW. Affective and neuropsychological correlates of children's rituals and compulsive-like behaviors: continuities and discontinuities with obsessive-compulsive disorder. Brain Cogn. 2007;65:36-46.

21. Eisenberg N, Valiente C, Spinrad TL, Cumberland AJ, Liew J, Reiser M, et al, Longitudinal relations of children's effortful control, impulsivity, and negative emotionality to their externalizing, internalizing, and co-occurring behavior problems. Dev Psychol. 2009;45(4):988-1008.

22. Hughes C, Ensor R. Individual differences in growth in executive function across the transition to school predict externalizing and internalizing behaviors and children's self-perceived academic success at age 6. J Exp Child Psychol. 2011;108:663-76.

23. Murray KT, Kochanska G. Effortful control: relation to externalizing and internalizing behaviors and factor structure. JACP. 2002;30:503-14.

24. Larkin F, Meins E, Centifanti LCM, Fernyhough C, \& Leekam SR. How does repetitive behavior relate to language and social cognition in typical development? Dev Psychopathol. 2016;29(3):863-74.

25. Adamek L, Nichols S, Tetenbaum JB, Ponzio C, Carr EG. Individual temperament and problem behavior in children with autism spectrum disorders. Focus Autism Other Dev Disabl. 2010;26:173-84.

26. De Pauw SSQ, Mervielde I, Van Leeuwen KG, De Clercq BJ. How temperament and personality contribute to the maladjustment of children with autism. J Autism Dev Disord. 2011;41:196-212.

27. Faja S, Dawson G. Reduced delay of gratification and effortful control among young children with autism spectrum disorders. Autism. 2015;19(1): 91-101.

28. Hill EL. Evaluating the theory of executive dysfunction in autism. Dev Rev. 2004;24(2):189-233.

29. Hollocks M, Jones C, Pickles A, Baird G, Happe F, Simonoff E. The association between social cognition and executive functioning and symptoms of anxiety and depression in adolescents with autism spectrum disorders. Autism Res. 2014;7(2):216-28.

30. Schwartz CB, Henderson HA, Inge AP, Zahka NE, Coman DC, Kojkowski NM, et al. Temperament as a predictor of symptomatology and adaptive functioning in adolescents with high-functioning autism. J Autism Dev Disord. 2009;39:842-55.

31. Wallace GL, Kenworthy L, Pugliese CE, Popal HS, White El, Brodsky E, Martin A. Real-world executive functions in adults with autism spectrum disorder: 
profiles of impairment and associations with adaptive functioning and comorbid anxiety and depression. J Autism Dev Disord. 2016;46(3):1071-83.

32. Lidstone J, Uljarević M, Sullivan J, Rodgers J, McConachie H, Freeston M, et al. Relations among restricted and repetitive behaviors, anxiety and sensory features in children with autism spectrum disorders. Res Autism Spectr Disord. 2014;8(2):82-92.

33. Magiati I, Ong C, Lim XY, Tan JW, Ong AY, Patrycia F, et al. Anxiety symptoms in young people with autism spectrum disorder attending special schools: associations with gender, adaptive functioning and autism symptomatology. Autism. 2016;20(3):306-20.

34. Rodgers J, Glod M, Connolly B, McConachie H. The relationship between anxiety and repetitive behaviours in autism spectrum disorders. J Autism Dev Disord. 2012;42(11):2404-9.

35. Wigham S, Rodgers J, South M, McConachie HR, Freeston MH. The interplay between sensory processing abnormalities, intolerance of uncertainty, anxiety and restricted and repetitive behaviours in autism spectrum disorder. J Autism Dev Disord. 2015;45:943-52.

36. Hoekstra RA, Vinkhuyzen AA, Wheelwright S, Bartels M, Boomsma DI, BaronCohen $\mathrm{S}$, et al. The construction and validation of an abridged version of the autism-spectrum quotient (AQ-short). J Autism Dev Disord. 2011;41(5): 589-96.

37. Barrett SL, Uljarevic M, Baker EK, Richdale AL, Jones CRG, Leekam SR. The Adult Repetitive Behaviours Questionnaire-2 (RBQ-2A): a self-report measure of restricted and repetitive behaviours. J Autism Dev Disord. 2015;45(11): 3680-92.

38. Evans DE, Rothbart MK. Developing a model for adult temperament. J Autism Dev Disord. 2007:41(4):868-88.

39. Knappe S, Klotsche J, Strobel A, LeBeau RT, Craske MG, Wittchen HU Beesdo-Baum K. Dimensional anxiety scales for DSM-5: sensitivity to clinical severity. Eur Psychiatry. 2013;28(7):448-56.

40. LeBeau RT, Glenn DE, Hanover LN, BeesdoBaum K, Wittchen HU, Craske MG. A dimensional approach to measuring anxiety for DSM-5. Int J of Methods Psychiatr Res. 2012;21(4):258-72.

41. Beesdo-Baum K, Klotsche J, Knappe S, Craske MG, LeBeau RT, Hoyer J, Strobel A, Pieper L, Wittchen HU. Psychometric properties of the dimensional anxiety scales for DSM-5 in an unselected sample of German treatment seeking patients. Depress Anxiety. 2012;29(12):1014-24.

42. IBM Corp. Released 2012. IBM SPSS Statistics for Windows, Version 21.0. Armonk, NY: IBM Corp.

43. Hayes AF. PROCESS: a versatile computational tool for observed variable mediation, moderation, and conditional process modeling [white paper] Retrieved from http://afhayes.com/public/process2012.pdf. 2012.

44. Baron RM, Kenny DA. The moderator mediator variable distinction in social psychological-research-conceptual, strategic, and statistical considerations. J Pers Soc Psychol. 1986;51(6):1173-82.

45. Sobel ME. Asymptotic confidence intervals for indirect effects in structural equation models. Sociol Methodol. 1982;13:290-312.

46. Shrout PE, Bolger N. Mediation in experimental and non-experimental studies: new procedures and recommendations. Psychol Methods. 2002;7(4):422-45.

47. White SW, Oswald D, Ollendick T, Scahill L. Anxiety in children and adolescents with autism spectrum disorders. Clin Psychol Rev. 2009;29:216-29.

48. van Steensel FJ, Bogels SM, Perrin S. Anxiety disorders in children and adolescents with autistic spectrum disorders: a meta-analysis. Clin Child Fam Psychol. 2011;14:302-17.

49. Uljarevic M, Nuske H, Vivanti G. Anxiety in autism spectrum disorder. In L. Mazzone \& B. Vitiello (Eds.), psychiatric symptoms and comorbidities in autism spectrum disorder (pp. 21-38). Cham: Springer International Publishing; 2016.

50. Evans DW, Kleinpeter FL, Slane MM, Boomer KB. Adaptive and maladaptive correlates of repetitive behavior and restricted interests in persons with Down syndrome and developmentally-matched typical children: a two-year longitudinal sequential design. PLoS One. 2014;9:e93951.

51. Uljarevic M. Repetitive behaviours, anxiety and sensory problems in children with autism and correlates of anxiety in their parents. PhD Thesis, Cardiff University; 2013

52. Magiati I, Lerh JW, Hollocks MJ, Uljarević M, Rodgers J, McConachie H, ... \& Simonoff E. The measurement properties of the spence children's anxiety scale-parent version in a large international pooled sample of young people with autism spectrum disorder. Autism Res.

53. Uljarević $M$, Nuske $H$, \& Vivanti $G$. Anxiety in autism spectrum disorder. $P$ 21-38. In L, Mazzone, B, Vitiello, (Eds.) Psychiatry comorbidity in autism spectrum disorders. Springer; 2016.
54. National Institute for Health and Care Excellence. Autism: the management and support of children and young people on the autism spectrum. (Clinical guideline 170); 2013.

55. Grahame V, Brett D, Dixon L, McConachie H, Lowry J, Rodgers J, et al. Managing repetitive behaviours in young children with autism spectrum disorder (ASD): pilot randomised controlled trial of a new parent group intervention. J Autism Dev Disord. 2015;45(10):3168-82.

56. Diamond A, Barnett WS, Thomas J, Munro S. Preschool program improves cognitive control. Science. 2007;318:1387-8.

57. Rueda MR, Posner MI, Rothbart MK. The development of executive attention: contributions to the emergence of self-regulation. Dev Neuropsychol. 2005;28:573-94.

58. Thorell LB, Lindqvist S, Nutley SB, Bohlin G, Klingberg T. Training and transfer effects of executive functions in preschool children. Dev Sci. 2009; 12:106-13.

59. Cannon L, Kenworthy L, Alexander KC, Werner MA, Anthony LG. Unstuck and on target!: an executive function curriculum to improve flexibility for children with autism spectrum disorders. Baltimore: Paul H. Brookes Pub. Co.; 2011.

60. Kenworthy L, Anthony LG, Naiman DQ, Cannon L, Wills MC, Luong-Tran C, et al. Randomized controlled effectiveness trial of executive function intervention for children on the autism spectrum. J Child Psychol Psychiatry. 2014;55:374-83.

61. Gross JJ. The emerging field of emotion regulation: an integrative review. Rev Gen Psychol. 1998;2(3):271-99.

62. Fan J, McCandliss BD, Sommer T, Raz M, Posner MI. Testing the efficiency and independence of attentional networks. J Cognitive Neurosci. 2002;14: 340-7.

\section{Submit your next manuscript to BioMed Central and we will help you at every step:}

- We accept pre-submission inquiries

- Our selector tool helps you to find the most relevant journal

- We provide round the clock customer support

- Convenient online submission

- Thorough peer review

- Inclusion in PubMed and all major indexing services

- Maximum visibility for your research

Submit your manuscript at www.biomedcentral.com/submit 